\title{
Letter
}

\section{Mutagenicity of octane and tetrasodium pyrophosphate in bacterial reverse mutation (Ames) test}

\author{
Soo-Jin Kim, Kyung-Taek Rim, Hyeon-Yeong Kim and Jeong-Sun Yang \\ Center for Chemical Safety and Health, Occupational Safety and Health Research Institute, KOSHA 104-8, \\ Munji-dong, Yuseong-gu, Daejeon 305-380, KOREA
}

(Received February 4, 2010; Accepted March 3, 2010)

\begin{abstract}
We investigated the genotoxicities or mutagenicities of 2 chemicals (octane and tetrasodium pyrophosphate) with limited toxicological data in spite of their common usage based on Ames reverse mutation test. In this test, treatment of 2 chemicals at each five dose did not induce mutagenicity in Salmonella typhimurium TA98, TA100, TA1535, TA1537, and in Escherichia coli WP2uvrA with and without metabolic activation. These results indicate that 2 chemicals do not have mutagenic potentials under the conditions examined in each study. Despite these results, it can affect by inducing inhalation, skin or eye contact, ingestion, and have affected central nervous system as a target organ. It is thus necessary to prepare the local exhaust system and personal protective equipments. Based on this study, we suggest that future studies should be directed toward chronic inhalation, carcinogenic test and so on.
\end{abstract}

Key words: Reverse mutation, Octane, Tetrasodium pyrophosphate

\section{INTRODUCTION}

It being increased the necessity of hazard assessment with many chemicals because of the increase of exposure frequency to workers as developing the chemical industries.

It was performed the bacterial reverse mutation (Ames) test of 2 chemicals, octane (CAS No. 111-65-9) and tetrasodium pyrophosphate (CAS No. 7722-88-5) which was not sufficient its definite information but increased the necessity of hazard assessment.

Moreover it would make use of the toxicological information of these 2 chemicals for workers' right of known, to prepare or update the material safety data sheet (MSDS) of it.

Octane is the typical organic liquid (European commission, 2000), and its threshold limit values in workplace are MAK (DE) $2,350 \mathrm{mg} / \mathrm{m}^{3}$, TLV (US) $300 \mathrm{mg} / \mathrm{m}^{3}$, TLV-TWA $1,400 \mathrm{mg} / \mathrm{m}^{3}$ (ACGIH, 2009). The substance is manufactured in a closed system, and exposure is possible during sampling. In using products such as paints and inks, users may be exposed to this substance. The physicochemical properties are that melting point $-56.8^{\circ} \mathrm{C}$, boiling point $125.5^{\circ} \mathrm{C}$ at $1,000 \mathrm{hPa}$, vapor pressure $15 \mathrm{hPa}$ at $20^{\circ} \mathrm{C}$, flash point $12^{\circ} \mathrm{C}$ and have very low water solubility
(Registry of Toxic Effects of Chemicals Substances Database, 1993).

Analyses of urinary metabolites were performed by gas-chromatography, gas-liquid chromatography and gasliquid chromatography/mass spectrometry. The metabolites included 2-octanol, 3-octanol, 5-oxohexanoic acid and 6-oxoheptanoic acid. The sex of the animals influenced the relative amounts of metabolites formed. No kidney damage was found as a result of n-octane dosing (Olson et al., 1986).

When the isooctane and $\mathrm{n}$-octane vapors were ${ }^{14} \mathrm{C}$ labeled, the radioactivity in exhalent, urine, and feces was determined for $70 \mathrm{hr}$ post exposure, after which residual radioactivity in the rat carcasses was determined. Absorbed ${ }^{14} \mathrm{C}$-isooctane equivalents were eliminated almost exclusively via the kidneys, while absorbed ${ }^{14} \mathrm{C}$ n-octane equivalents were excreted about equally via the kidneys and as $\mathrm{CO}_{2}$. Kidney excretion of isooctane-introduced ${ }^{14} \mathrm{C}$ was protracted over the entire $70 \mathrm{hr}$ post-exposure observation period, whereas for octane-introduced ${ }^{14} \mathrm{C}$, kidney excretion was essentially complete after 10 $20 \mathrm{hr}$. About $5 \%$ of the ${ }^{14} \mathrm{C}$ octane equivalents inhaled at $1 \mathrm{ppm}$ remained in the carcass $70 \mathrm{hr}$ after exposure (Dahl, 1989).

In acute inhalation toxicity, the $\mathrm{LC}_{50}$ in rat for $4 \mathrm{hr}$ is 
$25.1 \mathrm{ppm}$ (Gigiena Truda, 1957), the other routes LDLo in mouse through i.v. is $428 \mathrm{mg} / \mathrm{kg}$ bw (Registry of Toxic Effects of Chemicals Substances Database, 1993). According to the International Agency for Research on Cancer 1989 Monography, there is no adequate evidence of carcinogenicity in man for hydrocarbons solvents. Inhalation of concentrated vapors may cause irritation of respiratory tract, depression and pulmonary edema. Liquid can cause irritation of eyes and (on prolongated contact) irritation and cracking of skin. Ingestion causes irritation of mouth and stomach. Aspiration causes severe lung irritation, rapidly developing pulmonary edema, and central nervous system excitement, followed by depression (Registry of Toxic Effects of Chemicals Substances Database, 1993).

The target Organ is CNS and the symptoms of exposure may include burning sensation, coughing, wheezing, laryngitis and shortness of breath, headache, nausea and vomiting (Sigma-Aldrich, 2006).

Tetrasodium pyrophosphate (7722-88-5, European commission, 2000) have physicochemical properties that the melting point is ca. $990^{\circ} \mathrm{C}$ (ThermPhos International, 1997), water solubility ca. $20 \mathrm{~g} / 1$ at $20^{\circ} \mathrm{C}$ (ThermPhos International, 1997).

Its acute oral toxicity, the $\mathrm{LD}_{50}$ rat is over $2,000 \mathrm{mg} /$ $\mathrm{kg}$ bw (ThermPhos International, 1997). Its TLV is $5 \mathrm{mg} /$ $\mathrm{m}^{3}$ in OSHA (Sigma-Aldrich, 2009), and the dermal $\mathrm{LD}_{50}$ rabbit is $7,940 \mathrm{mg} / \mathrm{kg}$. As signs and symptoms of Exposure, the effects due to ingestion may include nausea, vomiting. To the best of our knowledge, the chemical, physical, and toxicological properties have not been thoroughly investigated. Its potential health effects are the inhalation may be harmful because it causes respiratory tract irritation. Skin may be harmful if absorbed through because it causes skin irritation. Eye contact causes eye irritation and ingestion may be harmful if swallowed.

Despite its increasing use, the available genotoxicity data on these 2 chemicals are still controversial. Thus it was evaluated to determine the genotoxicity or mutagenicity with Ames test. These chemicals already have been done with so many tests, but it had not performed the Ames test with them. In addition, there are few toxicological data on both chemicals, but the used amount of them also has been increased recently.

From this study, it was performed the reverse mutation assay both in direct method ( $24 \mathrm{hr}$ and $48 \mathrm{hr}$ treatment) and metabolism activated method for $6 \mathrm{hr}$ treatment in test with several strains.

This study should help to improve testing of chemicals by generally used genotoxicity testing methods as well as investigations on the underlying mechanism and the inter- pretation of genotoxicity data on chemicals with hazard.

\section{MATERIALS AND METHODS}

\section{Chemicals}

The tetrasodium pyrophosphate (Sigma-Aldrich, > 99\%, MO, USA, Lot No. 048K0048) was dissolved in vehicles (Acetone, 99.8\%, Merck, Darmstadt, Germany, Lot No. K38502214812) and diluted if appropriate prior to treatment of the bacteria. The octane (Sigma-Aldrich, $>99 \%$, Lot No. 16124AE) was added directly to the test systems and/or diluted prior to treatment.

Concurrent strain-specific positive and negative (solvent or vehicle) controls, both with and without metabolic activation, was included in each assay. Positive control concentrations that demonstrate the effective performance of each assay was selected. In this study, it was used sodium azide (WAKO, 98\%, Osaka, Japan, Lot No. KSJ6151), 9-aminoacridine (9AA) (WAKO, 98\%, Lot No. 03024JR), 2-(2-furyl)-3-(5-nitro-2-furyl)acrylamide (AF-2) (WAKO, 98\%, WAP0369) and 2-aminoanthracene (2AA) (WAKO, 95\%, KSF1039) as positive controls. Dimethyl sulfoxide (Sigma-Aldrich, 99.5\%, 037K0766) was used as a solvent.

\section{Test bacterial strains}

The cultures contain a high titer of viable bacteria (Sanyo, Moriguchi, Osaka, Japan, MDF-U3086S) was used in the experiment. Five strains include four strains of S. typhimurium (TA1535; TA1537 or TA97a or TA97; TA98; and TA100, Moltox, NC, USA, Lot No. 2374) that have been shown to be reliable and reproducibly responsive between laboratories. The strains also yield spontaneous reverting colony plate counts within the frequency ranges expected from the laboratories historical control data.

An appropriate minimal agar (e.g. containing VogelBonner minimal medium E and glucose, Junsei, Tokyo, Japan, Lot No. 2D1149) and an overlay agar containing histidine and biotin or tryptophan (Bacto-agar, BD, NJ, USA, Lot No. 7144748), to allow for a few cell divisions, is used (No. 2 Nutrient Broth, Oxoid, Cambridge, UK, Lot No. 612715; Shaker bath, Precision, VA, USA, Model 50, $180 \mathrm{rpm})$.

\section{Mutagenicity assay}

The most commonly used metabolic activation system is a cofactor supplemented post-mitochondrial fraction (S9, Moltox, Lot No. 2374) prepared from the livers of rodents treated with enzyme-inducing agents such as Aroclor 1254 or a combination of phenobarbitone and $\beta$ - 
Mutagenicity octane, tetrasodium pyrophosphate in Ames test

naphthoflavone.

The cytotoxicity test was detected by a reduction in the number of reverting colonies, a clearing or diminution of the background lawn, or the degree of survival of treated cultures. The cytotoxicity of a substance may be altered in the presence of metabolic activation systems. The recommended maximum test concentration for soluble noncytotoxic substances was $5 \mathrm{mg} /$ plate or $5 \mathrm{ml} /$ plate. Five different analyzable concentrations of the test substance were used.

For the plate incorporation method, without metabolic activation, usually $0.05 \mathrm{ml}$ or $0.1 \mathrm{ml}$ of the test solutions, $0.1 \mathrm{ml}$ of fresh bacterial culture (containing approximately 108 viable cells) and $0.5 \mathrm{ml}$ of sterile buffer are mixed with $2.0 \mathrm{ml}$ of overlay agar. For the assay with metabolic activation, usually $0.5 \mathrm{ml}$ of metabolic activation mixture containing an adequate amount of post-mitochondrial fraction (in the range from 5 to $30 \% \mathrm{v} / \mathrm{v}$ in the metabolic activation mixture) are mixed with the overlay agar $(2.0 \mathrm{ml})$, together with the bacteria and test substance/test solution. The contents of each tube are mixed and poured over the surface of a minimal agar plate. The overlay agar is allowed to solidify before incubation.

For the preincubation method the test substance/test solution is preincubated with the test strain (containing approximately 108 viable cells) and sterile buffer or the metabolic activation system $(0.5 \mathrm{ml})$ usually for $20 \mathrm{~min}$ or more at $30 \sim 37^{\circ} \mathrm{C}$ prior to mixing with the overlay agar and pouring onto the surface of a minimal agar plate. Usually, 0.05 or $0.1 \mathrm{ml}$ of test substance/test solution, 0.1 $\mathrm{ml}$ of bacteria, and $0.5 \mathrm{ml}$ of S9-mix or sterile buffer, are mixed with $2.0 \mathrm{ml}$ of overlay agar. Tubes were aerated during pre-incubation by using a shaker.

For an adequate estimate of variation, triplicate plating was used at each dose level. All plates in a given assay were incubated at $37^{\circ} \mathrm{C}$ for $48 \sim 72 \mathrm{hr}$. After the incubation period, the number of reverting colonies per plate is counted.

\section{Evaluation and analysis of results}

Besides cytotoxicity, precipitation and viability the number of reverting colonies per plate was determined (Bio-multiscanner, BMS-400 system, Toyo Sokki, Kanagawa, Japan). The mutant frequency was expressed as the quotient of the number of reverting colonies over the number of colonies in the negative control.

A mutagenic potential of a test item was assumed if the mutant frequency is 2.0 or higher. A possible mutagenic potential was assumed if the quotient ranges between 1.7 and 1.9 in combination with a dose effect relationship. No mutagenic potential was assumed if all quotients range between 1.0 (and lower) to 1.6.

\section{RESULTS AND DISCUSSION}

In this test, treatment of 2 chemicals at each five dose did not induce mutagenicity in Salmonella typhimurium TA98, TA100, TA1535, TA1537 and in Escherichia coli WP2uvrA with and without metabolic activation. These results indicate that 2 chemicals do not have mutagenic potentials under the conditions examined in each study.

All Salmonella strains are histidine-, the used E. coli strain tryptophan dependent.

Revertants are identified as colonies that grow in low levels of histidine or tryptophan.

Frameshift and base-pair substitution defects are represented to identify of both types. Additional genetic markers serve to make the strains more sensitive to certain types of mutagens. Table 1 shows the results of the reverse mutation (Ames) assay using Salmonella and E. coli treated with octane without and with metabolic activation, and Table 2 shows the results of the same assay with tetrasodium pyrophosphate.

The Ames test is a biological assay to assess the mutagenic potential of chemical compounds. A positive test indicates that the chemical might act as a carcinogen (although a number of false-positives and false-negatives are known) (Mortelmans and Zeiger, 2000) As cancer is often linked to DNA damage, the test also serves as a quick assay to estimate the carcinogenic potential of a compound since it is difficult to ascertain whether standard carcinogen assays on rodents were successful. The procedure is described in a series of papers from the early 1970s by Bruce Ames and his group at the University of California, Berkeley (Ames et al., 1975).

Testing of chemicals for mutagenicity in Salmonella typhimurium is based on the knowledge that a substance that is mutagenic in the bacterium is more likely than not to be a carcinogen in laboratory animals, and thus, by extension, present a risk of cancer to humans. Although about three-fourths of chemicals that are positive in the Ames test are found to be rodent carcinogens, not all substances that cause cancer in laboratory animals are mutagenic in this assay. However, the ease, rapidity (results in 3 4 weeks) and low cost of the test make it an important tool for screening substances for potential carcinogenicity.

The test is used world-wide as an initial screen to determine the mutagenic potential of new chemicals and drugs because there is a high predictive value for rodent carcinogenicity when a mutagenic response is obtained (McCann et al., 1975; Sugimura et al., 1976; Zeiger, 


\section{S-J. Kim et al.}

Table 1. Reverse mutation (Ames) assay using Salmonella and E. coli treated with octane without (upper panel) and with metabolic activation (middle panel), respectively. The lower panel is positive control (without and with metabolic activation)

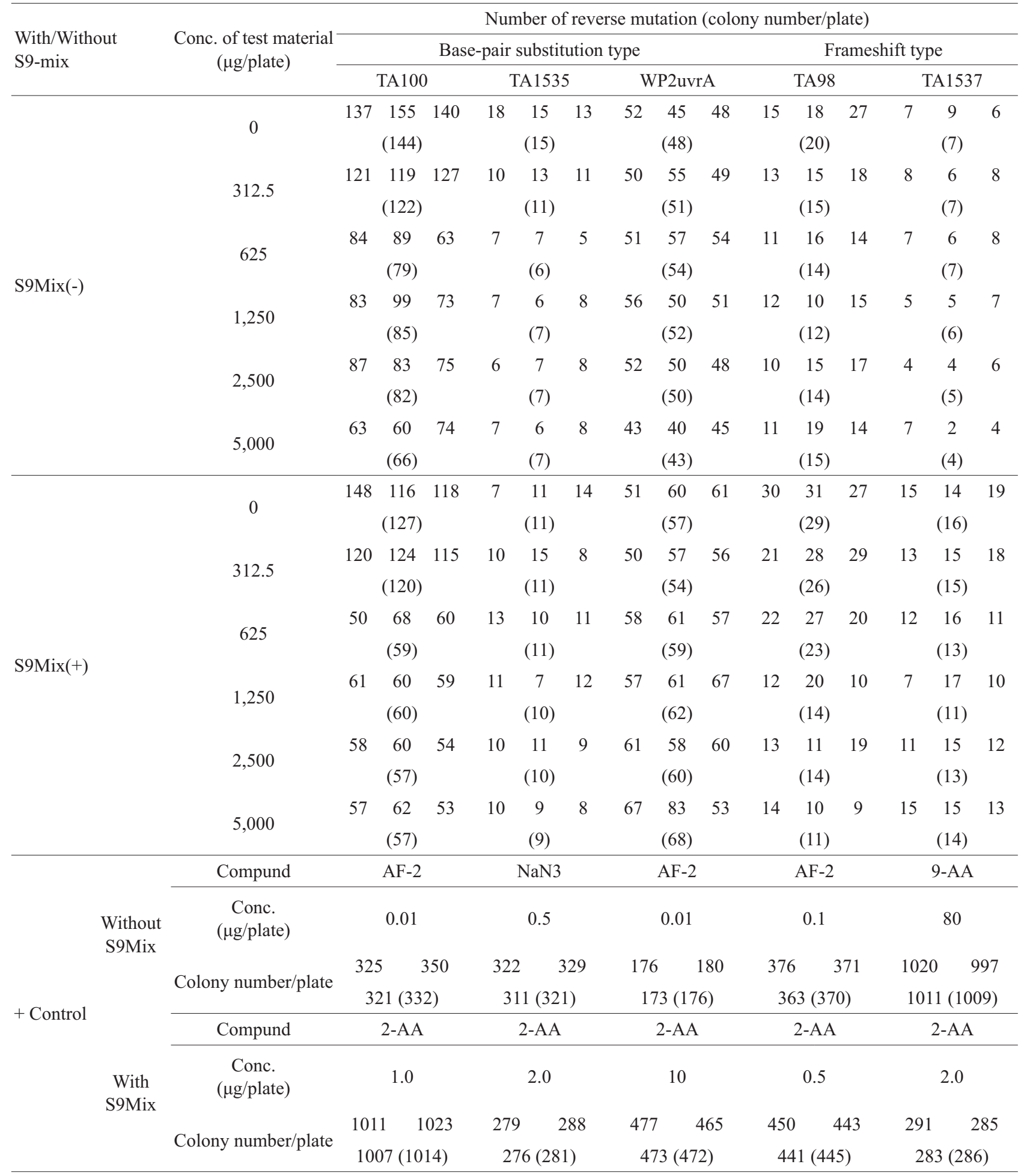

( ): mean value 
Mutagenicity octane, tetrasodium pyrophosphate in Ames test

Table 2. Reverse mutation (Ames) assay using Salmonella and E. coli treated with tetrasodium pyrophosphate without (upper panel) and with metabolic activation (middle panel), respectively. The lower panel is positive control (without and with metabolic activation).

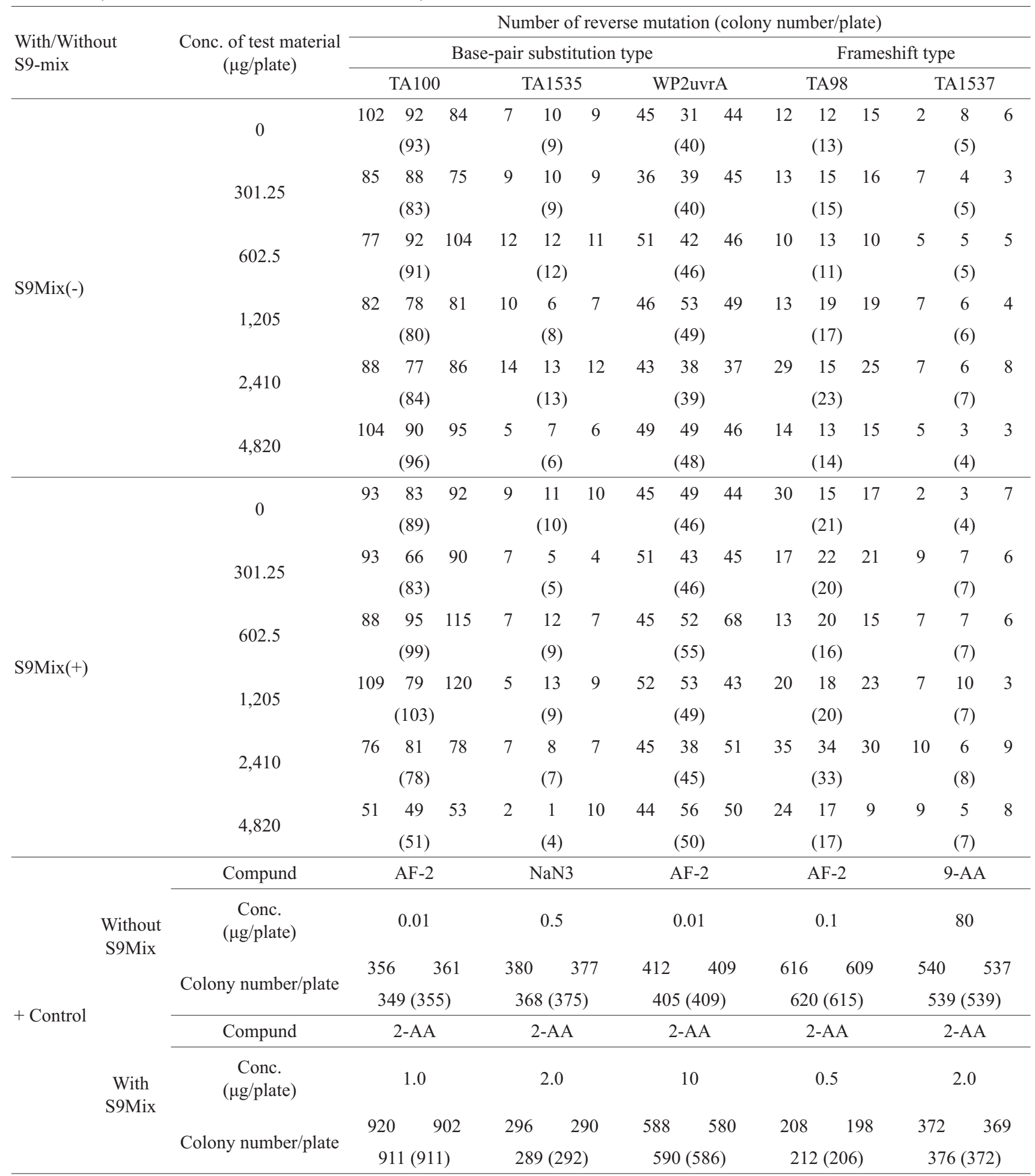

( ): mean value 
1985; Zeiger et al., 1990).

International guidelines have also been developed (e.g., OECD, ICH). For using by corporations and testing laboratories to ensure uniformity of testing procedures prior to submission of data to regulatory agencies for registration or acceptance of many chemicals, including drugs and biocides. Many validation studies have been performed to determine the reproducibility of test results on an intra- and inter-laboratory level (Dunkel et al., 1984; Dunkel et al., 1985; Margolin et al., 1984; Piegorsch and Zeiger, 1991; Purchase et al., 1978; Venitt et al., 1981; Zeiger, 1985).

In addition, many studies have been performed to determine the sensitivity and correlation of the Ames test with animal carcinogenicity studies. It has indeed been established that there is a high predictivity of a positive mutagenic response in the Ames test for rodent carcinogenicity, ranging from $90 \%$ to $77 \%$, the primary differences being the chemical composition of the compiled databases (Ames and McCann, 1976; McCann et al., 1975; Sugimura et al., 1976; Tennant et al., 1987; Zeiger, 1998).

Information on the mode of action (e.g. genotoxic potential) can influence the ultimate classification and levels of acceptable risk. In the EU, genotoxic carcinogens for which a clear threshold for response does not exist may be subject to different dose extrapolation methodologies to predict responses at very low doses. For genotoxic carcinogens, carcinogenicity is assessed using the T25 method which is defined as the chronic daily dose in $\mathrm{mg} / \mathrm{kg}$ per day that produces tumors in $25 \%$ of the animals after accounting for background tumor incidence (Dybing et al., 1997).

Carcinogenic effects brought about by secondary mechanisms, rather than through direct interaction of chemical (or metabolite) with DNA, could warrant a different risk assessment paradigm. An example is the increase in mutations caused by target tissue proliferation (EEC Annex VI to Directive 67/548/EC, 1967, as amended). On the approximation of laws, regulations and administrative provisions relating to the classification, packaging and labeling of dangerous substances.

Spontaneous mutations (those that occur by chance, not by chemical treatment) will appear as colonies on the control Petri dishes. If the test chemical was mutagenic to any particular strain of bacterium, the number of histidine-independent colonies arising on those plates will be significantly greater than the corresponding control plates for that strain of bacteria. The positive control plates are also counted, and the number of mutant colonies appearing on them must be significantly increased over the spontaneous control number for the test to be considered valid. Failure of the positive control chemical to induce mutation is reason to discard the experiment.

Several doses (usually at least 5) of each test chemical and multiple strains of bacteria are used in each experiment. In addition, cultures are set up with and without added liver S9 enzymes at varying concentrations. Therefore, a variety of culture conditions are employed to maximize the opportunity to detect a mutagenic chemical. In analyzing the data, the pattern and the strength of the mutant response are taken into account in determining the mutagenicity of a chemical. All observed responses are verified in repeat tests. If no increase in mutant colonies is seen after testing several strains under several different culture conditions, the test chemical is considered to be nonmutagenic in the Ames test (Mortelmans and Zeiger, 2000).

Moreover how these chemicals behave inside the organism is one of the big issues that need to be resolved. They could cause overload on phagocytes, cells that ingest and destroy foreign matter, thereby triggering stress reactions that lead to inflammation and weaken the body's defense against other pathogens. Some chemicals accumulate in organs; another concern is their potential interaction with biological processes inside the body. For instance, this may affect the regulatory mechanisms of enzymes and other proteins.

Experiences with other chemicals taught us, that mechanisms of genotoxic effects can be diverse and their elucidation can be demanding, while there often is an immediate need to assess the genotoxic hazard. Thus a practical and pragmatic approach is the use of a battery of standard genotoxicity testing methods covering a wide range of mechanisms.

The greater chemical reactivity of some chemicals results in increased production of reactive oxygen species (ROS), including free radicals. ROS production has been found in a diverse range of chemicals. ROS and free radical production is one of the primary mechanisms of toxicity; it may result in oxidative stress, inflammation, and consequent damage to proteins, membranes and DNA.

It was reported that the alkaline (pH.13) SCGE assay is very effective to detect base oxidation, DNA single strand breakage (SSB) with ROS. It is applied that the study with cellular repair activity with DNA segments for reveal or amplify the genotoxic effects and that measuring the repair activity with DNA repair enzymes or inhibition of DNA damage by antioxidants (Jekinson et al., 1999), and quantitative measurements of specific oxidative base (Collins et al., 1993; Covallo et al., 2003).

Despite these results, it can affect by inducing inha- 
Mutagenicity octane, tetrasodium pyrophosphate in Ames test

lation, skin or eye contact, ingestion, and have affected central nervous system as a target organ. It is thus necessary to prepare the local exhaust system and personal protective equipments. Based on this study, we suggest that future studies should be directed toward chronic inhalation, carcinogenic test and so on. So, it was suggested the further investigations to perform such as FLARE assay (Comet assay with repair enzyme as Fpg, Endo III), real time RT-PCR and the other genotoxic tests commonly used. Moreover it would be more useful as a biomarker for chemical risk assessment to perform these tests with many other chemicals.

\section{ACKNOWLEDGMENTS}

This work was supported by the Korea Occupational Safety \& Health Agency, Ministry of Labor, Republic of Korea, and Grant-in-Aid for chemical hazard assessment, 2009.

\section{REFERENCES}

American Conference of Governmental Industrial Hygienists (2009): Threshold Limit Values and Biological Exposure Indices. Ohio. USA.

Ames, B.N. and McCann, J. (1976): Detection of carcinogens as mutagens in the Salmonella/microsome test: assay of 300 chemicals: discussion. Proc. Natl. Acad. Sci. USA, 73, 950-954.

Ames, B.N., McCann, J. and Yamasaki, E. (1975): Methods for detecting carcinogens and mutagens with the Salmonella/mammalian-microsome mutagenicity test. Mutat. Res. 31, 347-364.

Collins, A.R., Duthie, S.J. and Dobson, V.L. (1993): Direct enzymic detection of endogenous oxidative base damage in human lymphocyte DNA. Carcinogenesis, 14, 1733-1735.

Cavallo, D., Ursini, C.L., Setini, A., Chianese, C., Piegari, P., Perniconi, B. and Iavicoli, S. (2003): Evaluation of oxidative damage and inhibition of DNA repair in an in vitro study of nickel exposure. Toxicol. in Vitro, 17, 603-607.

Dahl, A.R. (1989): Inhalation Toxicol. Res. Inst., Lovelace Biomed. And Environ. Res. Inst., P.O. Box 5890 Albuquerque NM 87185 USA. Toxicol. Appl. Pharmacol., 100, 334-341.

Dunkel, V.C., Zeiger, E., Brusick, D., McCoy, E., McGregor, D., Mortelmans, K., Rosenkranz, H.S. and Simmon, V.F. (1984): Reproducibility of microbial mutagenicity assays: 1 . Tests with Salmonella typhimurium and Escherichia coli using a standardized protocol. Environ. Mutagen., 6 (Suppl. 2), 1-254.

Dunkel, V.C., Zeiger, E., Brusick, D., McCoy, E., McGregor, D., Mortelmans, K., Rosenkranz, H.S. and Simmon, V.F. (1985): Reproducibility of microbial mutagenicity assays: II. Testing of carcinogens and noncarcinogens in Salmonella typhimurium and Escherichia coli. Environ. Mutagen., 7 (Suppl. 5), 1-248.

Dybing, E., Sanner, T., Roelfzema, H., Kroesse, D. and Tennant, R.W. (1997): T25: a simplified carcinogenic potency index: description of the system and study of correlations between carcinogenic potency and species/site specificity and mutagenicity. Pharmacol. Toxicol., 80, 272-279.

European commission (2000): IUCLID Dataset of Tetrasodium pyrophosphate. European Chemicals Bureau. http://ecb.jrc. ec.europa.eu/esis/index.php?PGM=dat

Gigiena Truda i Professional'nye Zabolevaniy (Labor Hygiene and Occupational Diseases) (1957): 32, 23, 88 V/O Mezhdurodnaya Kniga 113095 Moscow USSR, 1. As reported in Registry of Toxic Effects of Chemical Substances Database. 1993.

IARC (1989): Some organic solvents, resin monomers and related compounds, pigments and occupational exposures in paint manufacture and painting. IARC Monogr. Eral. Carcinog. Risks Hum., 47, 1-442.

International Commission on Harmonization (1995): Guidance on Specific Aspects of Regulatory Genotoxicity Tests for Pharmaceuticals: International Commission on Harmonisation of Technical Requirements for Registration of Pharmaceuticals for Human Use.

Jekinson, A.M., Collins, A.R., Duthie, S.J., Wahle, K.W.J. and Duthie, G.G. (1999): The effect of increased intakes of polyunsaturated fatty acids and vitamin E on DNA damage in human lymphocytes. FASEB J., 13, 2138-2142.

Margolin, B.H., Risko, K.J., Shelby, M.D. and Zeiger, E. (1984): Sources of variability in Ames Salmonella typhimurium tester strains: analysis of the International Collaborative Study on "genetic drift." Mutat. Res., 130, 11-25.

McCann, J., Choi, E., Yamasaki, E. and Ames, B.N. (1975): Detection of carcinogens as mutagens in the Salmonella/microsome test. Assay of 300 chemicals. Proc. Natl. Acad. Sci. USA, 72, 5135-5139.

McCann, J., Spingarn, N.E., Kobori, J. and Ames, B.N. (1975): Detection of carcinogens as mutagens: bacterial tester strains with R factor plasmids. Proc. Natl. Acad. Sci. USA, 72, 979-983.

Mortelmans, K. and Zeiger, E. (2000): The Ames Salmonella/microsome mutagenicity assay. Mutat. Res., 455, 29-60.

Olson, C.T., Yu, K.O., Hobson, D.W. and Serve, M.P. (1986): Toxic Hazards Div. Harry G. Armstrong Aerosp. Med. Res. Lab. Wright-Patterson AFB, OH 45433 USA. Toxicol. Lett., 31, 147150 .

Organisation for Economic Co-operation and Development (1997): Guideline for Testing of Chemicals, Test Guideline 471: Bacterial Reverse Mutation Test. Paris.

Piegorsch, W.W. and Zeiger, E. (1991): Measuring intra-assay agreement for the Ames Salmonella assay, in: L. Hothorn (Ed.), Statistical Methods in Toxicology, Lect. Notes Med. Informatics 43, pp.35-41, Springer, Heidelberg.

Purchase, I.F.H., Longstaff, E., Ashby, J., Styles, J.A., Anderson, D., Lefevre, P.A. and Westwood, F.R. (1978): An evaluation of 6 short-term tests for detecting organic chemical carcinogens. Br. J. Cancer, 37, 873-903.

Sigma-Aldrich. (2006): MSDS of Octane. MO. USA.

Sigma-Aldrich. (2009): MSDS of Tetrasodium pyrophosphate. MO. USA.

Sugimura, T., Sato, S., Nagao, M., Yahagi, T., Matsushima, T., Seino, Y., Takeuchi, M. and Kawachi, T. (1976): Overlapping of carcinogens and mutagens, in: Magee, P.N., Takayama, S., Sugimura, T. and Matsushima, T. (Eds.), Fundamental of cancer prevention, pp.191-215, University Tokyo Press, Baltimore.

Tennant, R.W., Margolin, B.H., Shelby, M.D., Zeiger, E., Haseman, J.K., Spalding, J., Resnick, W., Stasiewicz, M., Anderson, B. and Minor, R. (1987): Prediction of chemical carcinogenicity in rodents from in vitro genetic toxicity assays. Science, 236, 933941.

ThermPhos International B.V. (1997): EG-Sicherheitsdatenblatt THERMPHOS Pyro S 600 (Stand: 04.03.1996) 


\section{S-J. Kim et al.}

Venitt, S. and Crofton-Sleigh, C. (1981): Mutagenicity of 42 coded compounds in a bacterial assay using Escherichia coli and Salmonella typhimurium, in: deSerres, F.J. and Ashby, J. (Eds.), Evaluation of Short-Term Tests for Carcinogens. Report of the International Collaborative Program. Prog. Mutat. Res., 1, pp.351-360, Elsevier, New York.

Zeiger, E. (1985): The Salmonella mutagenicity assay for identification of presumptive carcinogens, in: Milman, H.A. and Weisburger, E.K. (Eds.). Handbook of Carcinogen Testing, pp.
83-99, Noyes Publishers, Park Ridge.

Zeiger, E. (1998): Identification of rodent carcinogens and noncarcinogens using genetic toxicity tests: premises, promises, and performance. Regul. Toxicol. Pharmacol., 28, 85-95.

Zeiger, E., Haseman, J.K., Shelby, M.D., Margolin, B.H. and Tennant, R.W. (1990): Evaluation of four in vitro genetic toxicity tests for predicting rodent carcinogenicity: confirmation of earlier results with 41 additional chemicals. Environ. Mol. Mutagen., 16 (Suppl. 18), 1-14. 